\title{
Game Mechanics supporting pervasive learning and experience in Games, Serious Games, and Interactive \& Social Media
}

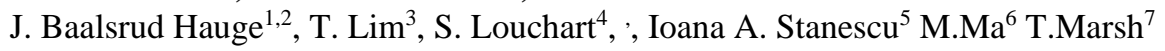

\author{
${ }^{1}$ Bremer Institut für Produktion und Logistik (BIBA) University of Bremen, Germany \\ ${ }^{2}$ Royal institute of Technology, Stockholm, Sweden \\ ${ }^{3}$ Heriot-Watt University, Scotland, UK \\ ${ }^{4}$ The Glasgow School of Art (DDS), Scotland, UK \\ ${ }^{5}$ Advanced Technology Systems, Targoviste, Romania \\ ${ }^{6}$ University of Huddersfield, UK \\ ${ }^{7}$ Griffith University, Griffith Film School, Brisbane, Australia \\ t.lim@hw.ac.uk, s.louchart@gsa.ac.uk, baa@biba.uni-bremen.de, Ioana.stanescu@ats.com.ro \\ M.Ma@hud.ac.uk, dr.tim.marsh@gmail.com
}

\begin{abstract}
.
This workshop focuses on defining the mechanisms required for pervasive gameplay and interaction to inform, educate, and reflect with game supported learning. The objective is for participants to share, discuss and learn about existing relevant mechanisms for pervasive learning in a socially-nurtured Serious Game (SG) context.

Research in SG, as a whole, faces two main challenges: understanding the transition between the instructional design and actual game design implementation [1], and providing an evidence-based mapping of game design patterns onto relevant pedagogical patterns [2]. Essentially, the transition lacks methodology and requires a leap of faith from a prospective customer to the ability of a SG developer to deliver a game that will achieve the desired learning outcomes. This workshop aims to present and apply a preliminary exposition though a purpose-processing methodology to probe, from various SG design aspects, how serious game design patterns map with pedagogical practices
\end{abstract}

\section{Introduction}

The immersive nature and engaging qualities of games, SGs, and interactive social media play an important role in the way information is provided and exchange facilitated. The three main synergistic areas of focus for this workshop are therefore:

1. To learn, inform or make aware intra/inter SG-learning system relationships

2. To educate, encourage reflection, contemplation or deliberation

3. To determine pervasive mechanisms that influence behaviour change

There are a number of existing games and game communities that address research aspects of these areas. Amongst them are Games for Change [1], Persuasive Games [2] and Alternate Reality Games [3].

Experiences that resonate or linger following an encounter (gameplay, interaction) have been shown to encourage reflection and potentially act as trigger for behaviour change [4]. However, there are still several gaps in order to understand exactly how Serious Game Mechanics (SGM) interacts with Learning Mechanics. An improved understanding of the relation would help in the design of better pervasive game mechanics. 


\section{The SGM approach}

SGs, like games in general represent a complex system of intertwined experiences. They are designed to motivate a player not only to play and engage with a proposed experience, but also to express and reflect on a gaming activity during and after experiencing it. The game activities, various levels of SGM, motivational elements, competition, challenge etc. are all inter-related elements through which a gaming experience can be defined. Purposeful learning is an aspect specific to SGs. The methodological approach towards identifying SGMs is a simple approach which focuses on the nature of Game Mechanics associated with the specific aspect of purposeful learning [5]. All of these elements can be described in terms of Purpose, Process and Structure, in the sense that SGMs elements are designed with pedagogy in mind, while serving gaming and learning experiences [6, 7]. This purpose is generally achieved through a process in which activities, information or events represent the structural elements of the overall game element process (Figure 1).

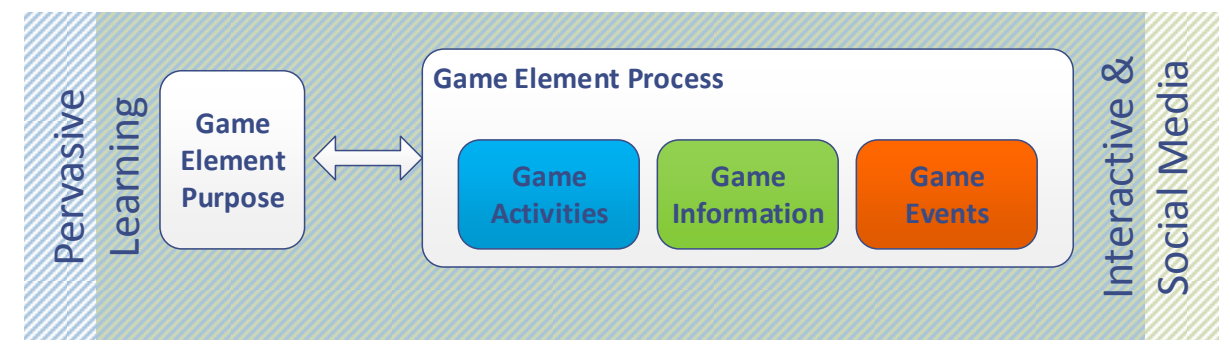

Figure 1 - Pervasive \& Social SG element methodological approach.

Pervasive technologies open up new opportunities for game-enhanced learning experiences. However, providing adapted game experiences based on the learner location remains an open challenge. Context/ location identification represents a first hurdle in generating customized sequences of learning. Defining context/ locationsensitive, user-centred customization sequences are still subject to debate.

Socially intense virtual experiments are powerful tools to engage learners. However it is equally important to consider not only their potential to stimulate learners, but also to annoy them. Maintaining a balanced stimulus based on Social Media is a key ingredient in achieving success. Social networks should play a critical role in stimulating learning, it is important to achieve an in-depth understanding on how to balance the amount of information posted on social networks and how revealing the information is.

\section{Objective}

This workshop focuses on identifying and analyzing the criteria of design, development and assessment of pervasive, socially textured gaming methods and technologies (mechanics, procedures, actions, mechanisms, systems, story, etc.) [8, 9] that interactively inform and educate, develop skills, encourage reflection, raise awareness, and influence behaviour change. 
Specific objectives include: 1) Identify opportunities and challenges associated with SGs implemented in context-aware, socially intensive environments. 2) Analyse the transformation processes of SGM and of pedagogical constructs in pervasive and social contexts. 3)Validate the extension of the Purpose-Processing Methodology (PPSM) based on pervasive and social experiences. 4) Discuss the pedagogical implications of adaptive learning experiments.

In particular, we intend to discuss how the different aspects mentioned below influence the SGM-LM interaction in pervasive and social contexts: a) Mechanics/experience to inform or provide a message or argument. b) Character and role-play to enact / become complicit in historical, social and perhaps difficult events/scenarios; c) Techniques for embedding messages and arguments in interactive story; d) Entertaining and non-entertaining gameplay/interaction; e) Encourage reflection during and following an encounter (gameplay, interaction); f) Blended approaches using technology and non-technology, \& in-game and off-game approaches g) Gamification - applying gaming characteristics to non-gaming activities; h) Motivating and sustaining behaviour change

\section{Target Participants and workshops length}

The workshop targets designers, developers, evaluators and researchers from both academia and industry involved in the topics above. In addition, we are interested in educators and participants with an interest in games, SGs, social media and on-line design, to share and discuss the issues above.

The proposed workshop will last half a day and will run as follow:

1. Presentation of emerging blends of technologies that impact learning experiences: Serious Games Mechanics, Pervasive Learning \& Social Media

SGMs are seen as the relationship between pedagogical patterns and game design patterns [5]. The process of investigating the links between the two lies between the instructional design requirements and the actual game/game-play design. This session will provide a definition of SGM and suggest an updated purpose-processing methodology (PPSM) to identify the link. The extension of the methodology to incorporate Pervasive Learning and Social Media are discussed.

\section{Game play session}

The participants will experiment the presented methodological approach and framework. Participants will be divided into groups working with two different aims: 1) to analyze existing games from a pervasive and social perspective; and 2) to design new gameplays that take advantage of the benefits of pervasive and social contexts. The organizers will provide a set of state of the art SGs to be played and analyzed.

3. SGM card game (90 min

This activity is based on the board game "cards against humanity". 
4. Reflection and conclusion (Games and Pedagogy) - (45 min)

Based upon the result of game play session, we will analyze, discuss and show how different aspects of the proposed methodological approach and framework can effectively support the design process, increasing the quality of the outcome and decreasing the time to market. We will also discuss typical challenges in the design process, as well as challenges in finding the right SGMs for specific purposes.

\section{Acknowledgments}

This workshop is based upon previous experience and similar workshop held at ICEC 2013 in Sao Paolo, Brazil, GameDays 2014 in Darmstadt, Germany and Gala Conference 2014 in Bucharest, Romania. Part of the work has been partially funded under the EC 7FRP GALA, Psymbiosys (EC H2020) and by the Unitatea Executiva pentru Finantarea Invatamantului Superior, a Cercetarii, Dezvoltarii si Inovarii (UEFISCDI) in Romania, Contract no. 19/ 2014 (DESiG).

\section{References}

1. Games for Change. http://www.gamesforchange.org

2. Alternate Reality Games. http://www.argn.com

3. Marsh, T. and Brigid, C. Lingering Serious Experience as Trigger to Raise Awareness, Encourage Reflection and Change Behavior. Persuasive Technology, 2013, Sydney. Springer Berlin Heidelberg, 116-124 (2013).

4. Bogost, I. Persuasive Games: The expressive power of videogames. The MIT Press (2007).

5. S. Arnab, T. Lim, M. B. Carvalho, F. Bellotti, S. de Freitas, S. Louchart, N. Suttie, R. Berta, A. De Gloria, "Mapping learning and game mechanics for serious games analysis", British Journal of Educational Technology, DOI: 10.1111/bjet.12113, 2014

6. Suttie, N., Louchart, S., Lim, T., Macvean, A., Westera, W., Brown, D., Djaouti, D.: Introducing the "Serious Games Mechanics" A Theoretical Framework to Analyse Relationships Between "Game” and "Pedagogical Aspects” of Serious Games, Procedia Computer Science, 15 (2012) 314-315

7. M. B. Carvalho, F. Bellotti, R. Berta, A. De Gloria, C. Islas Sedano, J. Baalsrud Hauge, J. $\mathrm{Hu}$, and M. Rauterberg, "An activity theory-based model for serious games analysis and conceptual design”, Computers \& Education, Volume 87, September 2015, Pages 166181, ISSN 0360-1315, http://dx.doi.org/10.1016/j.compedu.2015.03.023..

8. Bellotti, F., Kapralos, B., Lee, K., Moreno-Ger, P., Berta, R.: "Assessment in and of Serious Games: An Overview”. Advances in Human-Computer Interaction (2013), Article ID 136864 (2013) doi:10.1155/2013/136864

9. Bellotti F., Berta R. and De Gloria A., "Designing Effective Serious Games: Opportunities and Challenges for Research”, Special Issue: Creative Learning with Serious Games, Int.l Journal of Emerging Technologies in Learning (IJET), Vol. 5, 2010, pp. 22-35 